\title{
Advanced Passivity-Based Control for a Fuel Cell/Super-CaPaCitor Hybrid Power SYSTEM
}

\section{S. Kong, M. Hilairet, R. Roche}

FEMTO-ST, CNRS, Univ. Bourgogne Franche-Comte, UTBM

FCLAB, CNRS, Univ. Bourgogne Franche-Comte, rue Thierry Mieg, F-90010 Belfort Cedex, France. e-mail: suyao.kong@utbm.fr, mickael.hilairet@univ-fcomte.fr, robin.roche@utbm.fr

\begin{abstract}
An advanced passivity-based control is proposed to solve the converters coordination problem of a fuel cell/super-capacitor hybrid power system. Interconnection and Damping Assignment Passivity Based Control (IDA-PBC) is applied to design the controller. This nonlinear controller considers the state-of-charge of the super-capacitor and achieves the stability of the whole closed-loop system. Its feasibility for an electrical vehicle is proven by simulation results and a comparison with an earlier method.
\end{abstract}

Keywords - Energy Management, Fuel Cell, IDA-PBC, Passivity Based Control, Supercapacitors.

\section{INTRODUCTION}

Interconnection and Damping Assignment-Passivity Based Control (IDA-PBC) is applied in a fuel cell/super-capacitor hybrid power system. This nonlinear controller uses matrices that are related to the interconnection between the subsystems and the damping of the system to find a desired command that achieves the stability of the whole closed-loop system. M. Hilairet et al. [1] applied IDA-PBC for a regular two-converter parallel system with a fuel cell (FC) and supercapacitors (SCs). In their research, some terms of the general control were set to zero in order to obtain regular control strategies.

The novelty of this work is to exploit all the terms of the general non-linear control in order to integrate some components constraints directly in the control, while preserving the stability of the whole closed-loop system.

\section{ADVANCED POWER MANAGEMENT STRATEGY}

A two-converter parallel structure is used for the fuel cell/super-capacitors system shown in Fig. 1.

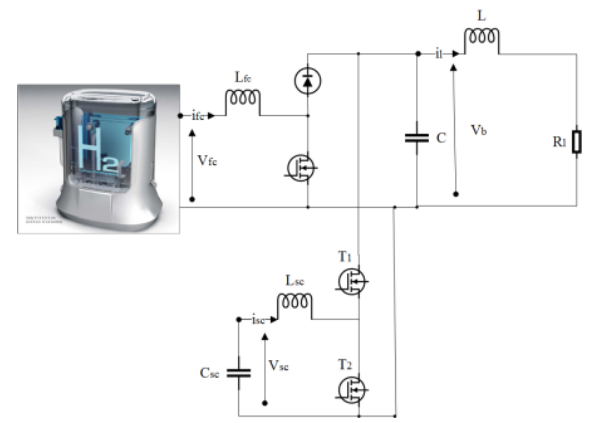

Fig. 1: System model

The main idea of the energy management strategy is to use the FC to supply the load and use the SCs during transients in order to stabilize the DC bus, with a proof of the stability of the whole closed-loop system.

Based on the previous strategy described in [1], a saturation of the SCs current is added to consider the state-of-charge of SCs by integrating a variable $r_{2}$. The control law is as follows:

$$
\begin{aligned}
& i_{s c}^{* *}=i_{s c}^{*}+r_{2} C_{s c}^{2} \tilde{v}_{s c} \\
& i_{f c}^{* *}=i_{f c}^{*}-r_{2} \frac{v_{s c}}{v_{f c}} C_{s c}^{2} \tilde{v}_{s c}
\end{aligned}
$$

where $i_{s c}^{*}, i_{f c}^{*}$ are control inputs obtained in [1], and $\tilde{v}_{s c}$ is the error between the voltage of super-capacitors and its equilibrium point.

\section{SIMULATION RESULTS}

Fig. 2 shows a comparison between the original control (in blue) proposed in [1] and the new one (in red). Here, the voltage of SCs is limited between $20.5 \mathrm{~V}$ and $21.5 \mathrm{~V}$ for the purpose of the test. It follows that the SCs current goes to 0 when the voltage exceeds the limitation around 20 and 30s. In order to counteract the injection of current in the DC bus, the FC current is naturally increased, and consequently preserves the stability of the whole closed-loop system.
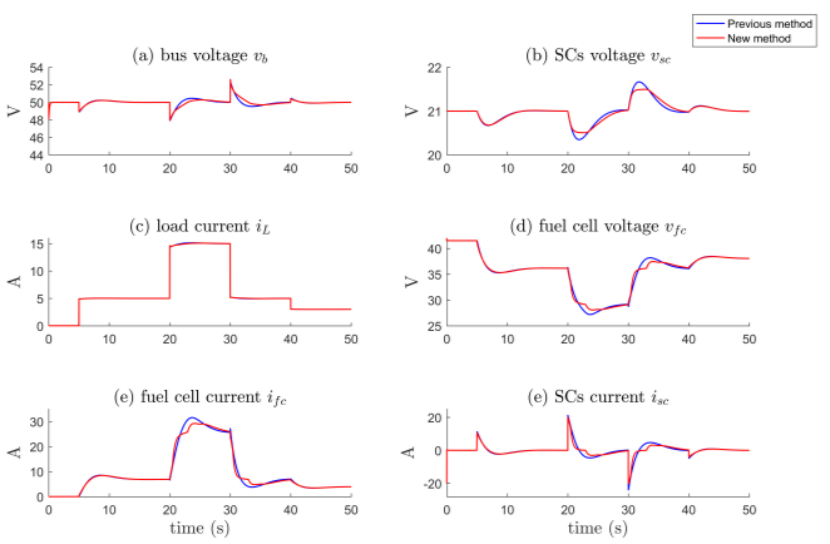

Fig. 2: Simulation results

\section{REFERENCES}

[1] M. Hilairet, M. Ghanes, O. Béthoux, V. Tanasa, J. Barbot, and D. Normand-Cyrot, "A passivity-based controller for coordination of converters in a fuel cell system," Control Engineering Practice, Vol. 21, no. 8, pp. 1097-1109, 2013. 